\section{Schnarchen, primäres}

Helga Peter

Marburg, Deutschland

\section{Englischer Begriff}

primary snoring

\section{Definition}

Veralteter, in der ICSD von 1990 noch gebräuchlicher Begriff zur Bezeichnung von kontinuierlichem und nicht mit Apnoen, Hypopnoen und Hypoventilation einhergehendem, vermutlich nicht gesundheitsgefährdendem $\triangleright$,Schnarchen“. Wegen seiner nicht schlaffragmentierenden Eigenschaft war es der Diagnosegruppe „Andere Parasomnien“ zugeordnet. In der > „ICSD-2“ (2005) ist die Diagnose ,primäres Schnarchen“ aufgrund der zwischenzeitlich fortgeschrittenen Präzisierung der $\triangleright$,Schlafbezogene Atmungsstörungen“ entfallen.

Siehe auch $\triangleright$,Schnarchen, kompensiertes“. 